$\begin{array}{ll}\text { Research Square } & \begin{array}{l}\text { Preprints are preliminary reports that have not undergone peer review. } \\ \text { They should not be considered conclusive, used to inform clinical practice, } \\ \text { or referenced by the media as validated information. }\end{array}\end{array}$

\title{
Effects of cognitive behavioral therapy on anxiety and depression in patients with chronic obstructive pulmonary disease:A Meta-analysis and Systematic Review
}

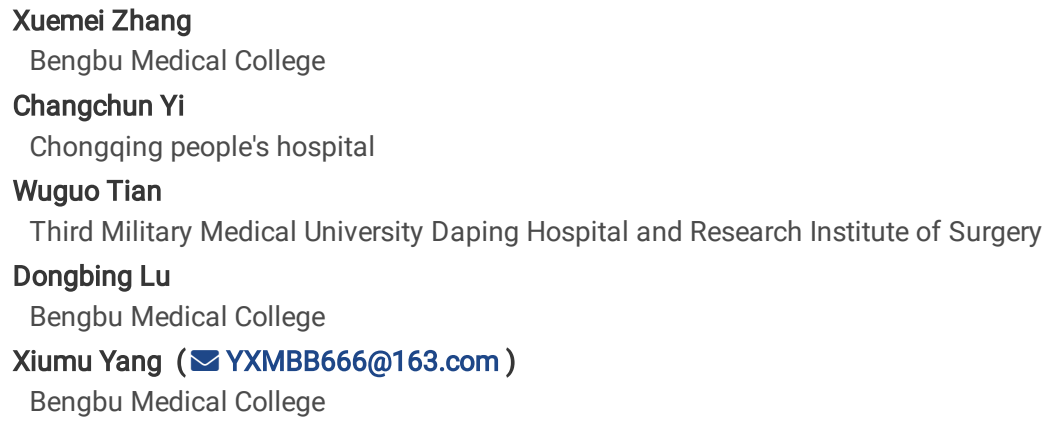




\section{Abstract}

Symptoms such as depression and anxiety are common psychiatric symptoms in patients with chronic obstructive pulmonary disease (COPD). Cognitivebehavioral therapy (CBT) is still controversial in the treatment of anxiety and depression in patients with COPD. We conducted a meta-analysis and systematic review to evaluate the effect of CBT on anxiety and depression in patients with COPD, with a view to providing some guidance for clinical application.Materials and Methods Computer search Web of Science, EMbase, PubMed, Cochrane Library, search time limit from the establishment of the library to August 2019.Collect the randomized controlled trial (RCT) for this topic. Two investigators independently screened the literature according to inclusion and exclusion criteria, extracted the data, and assessed the risk of bias in the included studies. Meta analysis using RevMan5.3 software.Results A total of 10 studies were included in a total of 1278 patients. Meta-analysis shows that cognitive behavioral therapy can improve depression and anxiety in patients with COPD. Subgroup analysis showed that intervention time $\geq 8$ weeks had significant differences in improving anxiety, while intervention time $<8$ weeks had significant differences in improving depression.Conclusion Cognitive-behavioral therapy can improve depression in COPD patients in a short period of time, and it takes longer to improve anxiety. Therefore, clinical practice can choose the appropriate intervention time according to the patient's psychological condition.

\section{Background}

Chronic Obstructive Pulmonary Disease (COPD) is a chronic disease of the respiratory system, which can reduce lung function and labor endurance year by year. In severe cases, life cannot take care of itself $[1,2]$. In addition to causing organic damage, COPD can seriously affect the quality of life and prognosis of

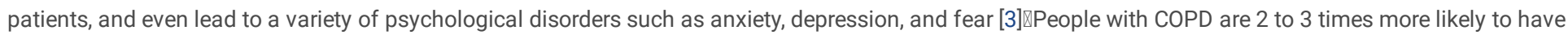
mental health problems than the general population [4, 5]. The prevalence of anxiety and depression in patients with COPD was $40 \%$ and $36 \%$, respectively. The data show that the prevalence of COPD combined with depression in the acute exacerbation period is as high as $86 \%$, and anxiety is as high as $55 \%$ in

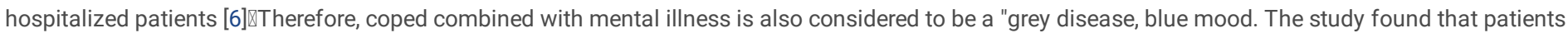
with COPD often fall into a vicious circle of dyspnea, decreased exercise capacity, inconvenient movement and social isolation. Anxiety and depression are the cycle. important part [7] $\triangle$ COPD patients with anxiety and depression often lack self-confidence or self-efficacy, leading to poor disease-related coping skills and poor self-care ability [8]. This indicates poor compliance with COPD medications with anxiety and depression, decreased exercise capacity and healthrelated quality of life, loss of labor, increased consumption of health resources, functional disability, and increased risk of acute exacerbations and deaths [9, 10]. Therefore, it is extremely important to identify patients' bad emotions early and manage them effectively [6]. However, the management of COPD psychological problems is still very poor [11]. Cognitive Behaviour Therapy (CBT) is a general term for cognitive treatment and behavioral techniques to change the cognitive and behavioral psychology of patients. It is an effective treatment for anxiety, depressive symptoms and physical health. Methods of dysfunction, there is evidence that it is effective for patients with COPD combined with anxiety and depression [12, 13]. Relevant evidence suggests that CBT is as effective as medication and may be the first choice for patients with mental health problems [14, 15]. However, the anxiety and depression of CBT intervention in patients with COPD has not been well confirmed. Taking into account the effects of these inconsistencies, we conducted a systematic review and meta-analysis of the subject's RCT to assess the effectiveness of CBT in the intervention of anxiety and depression in patients with coddle.

\section{Materials And Methods}

This review was conducted in accordance with the Preferred Reporting Items for Systematic Reviews and Meta-Analyses guidelines (PRISMA) [16] and the recommendations of the Cochrane Collaboration [17].

\section{Literature screening and identification of relevant studies}

Computer search Web of Science, EMbase, PubMed, Cochrane Library, search time limit from the establishment of the library to August 2019.The search term is Cognitive Behavioral Therapy, Chronic Obstructive Pulmonary Disease. The review of the retrieved articles by reading the titles and abstracts. Then, the full text of the likelihood relevant studies was examined for further. The following studies in the meta-analysis were firstly published in the primary literature with no reproduction in other studies.

\section{Inclusion criteria}

(1) Population: patients with COPD, all patients were treated with standard COPD medications, including bronchodilators, and oral corticosteroids and/or oxygenation when appropriate; (2) Intervention: cognitive behavioral therapy; (3) Comparison: usual care or health education intervention or blank control; (4) Study design: RCT, Language limited to English. (5) Outcome: anxiety and depression scale.

\section{Exclusion criteria}

(1) Incomplete data or misrepresentation of data reports; (2) repeated publication of documents; (3) case reports, reviews, etc.; (4) inability to obtain original documents. 


\section{Quality assessment and data extraction}

Two researchers (Xuemei Zhang and Changchun Yi) independently screened the literature and extracted the data. In the event of a disagreement, the third investigator (Wuguo Tian) was asked to judge. The extracted content includes author, publication date, country, sample size, age, type of CBT, content and duration, type of anxiety and depression scale, measurement data, intervention time, intervention details, etc.

The Cochrane Systematic Review Manual 5.1.0 recommended bias risk assessment method for risk assessment for inclusion in RCT. The main items are: 1) randomization plan; 2) group concealment; 3) blind method; 4) incomplete data reporting; 5) selective outcome report; 6) other sources of bias. Each item is evaluated as "high", "low" and "unclear".

\section{Data synthesis and statistical analysis}

RevMan5.3 (The Cochrane Collaboration, Software Update, Oxford, UK)) software for meta-analysis. Statistical results of continuous data were expressed as standardized mean difference (SMD). The heterogeneity between the included studies was analyzed by the $\chi 2$ test (test level is $\mathrm{a}=0.1$ ), and $\mathrm{l}^{2}$ was used to quantitatively determine the size of heterogeneity. When $\mathrm{P}<0.1$ and $/$ or $\mathrm{I}^{2}>50 \%$, the random effects model is used for the combined analysis, and conversely, the fixed effect model is used for the combined analysis. Sensitivity analysis of heterogeneity sources. Subgroup analysis was performed based on the time of intervention. Draw a funnel plot to assess possible publication bias and small sample bias, including Egger's method and Begg's method.

\section{Results}

A detailed overview of the study flow is presented in Figure 1. Ten studies $[12,13,18-25]$ comprising 1278 participants were included in the review. Characteristics of included studies are summarized in Tables 1 and 2. Part of the studies were deemed to be of moderate risk of bias (Figure2-3) because of inadequate blinding of participants and intervenors (an inherent challenge in CBT studies), allocation concealment and random sequence generation. The most commonly reported outcome measure for assessing anxiety and depression symptoms was the HADS, BAI and BDI.A detailed summary of outcome data is provided in Table 3.

\section{Symptoms of Anxiety}

1 item [12] The study did not report anxiety scores after intervention, the rest $[13,18-25]$ The results of the pooled study were SMD $=-0.28,95 \% \mathrm{Cl}[-0.51,0.05]$, $P=0.02$, and the difference was statistically significant (Figure 4).Subgroup analysis revealed no significant difference in the magnitude of difference between shorter and longer programs $(P=0.53)$. However, the effect in longer programs was statistically significant, while that of shorter programs was not data for this outcome were

statistically heterogeneous $\left(R^{2}=70 \%\right)$. Exploratory sensitivity analysis revealed the study of Lamers et al [25]. To be the likely source of this heterogeneity, with its exclusion from meta-analysis resulting in a revised $\mathrm{I}^{2}=34 \%$. The reason may be: in this study, the number of interventions per patient with CBT intervention resulted in different of 2 items $[12,20]$.

\section{Symptoms of Depression}

The study did not report anxiety scores after intervention, the rest $[13,18,19,21-25]$. The results of the combined analysis were SMD=-0.54, $95 \% \mathrm{Cl}$ $[-1.06,-0.02], P=0.04$, and the difference was statistically significant (Fig. 5). Subgroup analysis revealed no significant difference in the magnitude of difference between shorter and longer programs $(P=0.55)$. However, the effect in shorter programs was statistically significant, while that of longer programs was not. Data for this outcome were statistically heterogeneous $\left(I^{2}=92 \%\right)$. Exploratory sensitivity analysis revealed the study of Lamers et al [25]. To be the likely source of this heterogeneity, with its exclusion from meta-analysis resulting in a revised $\mathrm{I}^{2}=55 \%$. The reason may be: in this study, the number of interventions per patient with CBT intervention resulted in different of.

\section{Publication bias}

Publication bias assessment was performed using Egger's method and Begg's method. (Figure) suggests that there are no publication bias, anxiety (Egger's, $P=0.532$; Begg's, $P=0.823$ ), depression (Egger's, $P=0.322 ;$ Begg's, $P=0.960$ ). Figure 6 7.

\section{Discussion}

The incidence of anxiety, depression and panic in patients with COPD is significantly higher than that of normal people, which can increase the mortality rate of patients, reduce the quality of life and prognosis of patients, and increase the risk of acute exacerbation [6, 26-28]囚The efficacy of psychopharmacological treatment in COPD is limited and patients are often reluctant to take additional medication [29, 30]. Psychosocial intervention has been suggested as an alternative or complementary treatment strategy for reducing psychological distress and physical impairment [31, 32]. National Institute for Health and Care 
Excellence(NICE) [33] CBT is recommended as a treatment option for mental health problems in patients with chronic diseases and as an adjunct to other treatments. However, the effect of CBT intervention on anxiety and depression in patients with COPD is controversial. Our meta-analysis shows that CBT can effectively improve anxiety and depression in COPD patients. This with Smith at el [34] The results of the study are consistent. We conducted a subgroup analysis of the duration of the intervention and found that CBT short-term (<8weeks) intervention had no significant effect on improving patient anxiety, and depression showed significant differences. At the same time, Howard ${ }^{[21]}$ A 5-week CBT intervention in patients with COPD improved the patient's depression in the short term, and there was no significant difference in anxiety.Farver-Vestergaard [35]. The meta-analysis showed that CBT seems to be effective in improving the psychological status of patients with COPD, but the study was a combined analysis of Psychological (anxiety + depression) without a separate analysis of anxiety or depression, providing limited evidence. Our meta-analysis shows that CBT not only improves anxiety and depression in patients with COPD, but depression can be improved in a short period of time.

Coventry [36] Inclusion of 3 RCT and 1 non-RCT for meta-analysis, when CBT is combined with exercise and education, can reduce anxiety and depression in patients with COPD; but the evidence provided is valid. Small medium-quality RCT [18].The results show that CBT combined with exercise training and health education, anxiety and depression have significant therapeutic effects. Our meta-analytic inclusion of RCT, cbt interventions in a variety of forms, can be tailored to the actual situation of patients to develop a personalized cognitive behavioral intervention program. Traditional CBT has a long duration, operation

Frequent, high economic costs $[37,38]$ and there is not enough evidence to show which specific form of CBT treatment is best. Currently, telephoneadministered CBT intervention, Mindfulness-based CBT and Nurse-led CBT, etc. $[13,19,20]$. The new CBT intervention model came into being, and different new, cost-effective CBTs should be further developed in the future.

\section{Limitations}

Our meta-analysis has certain limitations. First of all, our analysis is based on 10 rct, with 4 items $[12,18,22,23]$.The RCT sample size is small. Compared with the larger sample, it is more likely to overestimate the treatment effect in the smaller experiment. Our study is heterogeneous, although the sensitivity is found by using the culling method to find the source of heterogeneity. , remove Lamers et al [25] After the study, the heterogeneity has decreased, but there is still some heterogeneity; the generation of the randomized scheme of RCT, the allocation of concealment, the implementation of blind method, etc. may have certain methodological heterogeneity, different cbt The frequency of treatment, the degree of anxiety and depressive symptoms before intervention, age, different outcome assessment tools, and fev $1 \%$ lead to possible risk of bias.

\section{Conclusion}

CBT can improve the depression of patients with COPD in a short period of time, and it takes longer to improve anxiety.

\section{Abbreviations}

COPD: Chronic obstructive pulmonary disease; CBT: Cognitive-behavioral therapy; RCT: Randomized controlled trial; SMD: standardized mean difference; NICE: National Insti-tute for Health and Care Excellence.

\section{Declarations}

\section{Availability of data and materials}

The datasets used and/or analyzed during the current study are available from the corresponding author on reasonable request.

\section{Authors' contributions}

ZXM and YXM contributed to the conception and design of the study, or acquisition of data, or analysis and interpretation of data; ZXM and YCC drafted the article or revising it critically for important intellectual content; TWG and LDB gave the final approval of the version to be submitted.

\section{Ethics approval and consent to participate}

This study did not involve human subjects, so informed consent was not required. In addition, no approval was required from an institutional review board.

\section{Consent for publication}

Not applicable.

\section{Competing interests}

The authors declare that they have no competing interests

\section{Acknowledgements}

Not applicable. 
None.

\section{References}

[1]. Pollok J, van Agteren $\mathrm{J}$ and Carson-Chahhoud K. Pharmacological interventions for the treatment of depression in chronic obstructive pulmonary disease[J].The Cochrane database of systematic reviews. 2018; 12(12): CD012346.

[2]. Burkes RM and Donohue JF. An Update on the Global Initiative for Chronic Obstructive Lung Disease 2017 Guidelines With a Focus on Classification and Management of Stable COPD[J]. Respiratory Care. 2018; 63(6):749.

[3]. Usmani ZA, Carson KV, Heslop K, et al.Psychological therapies for the treatment of anxiety disorders in chronic obstructive pulmonary disease [J] Cochrane Database of Systematic Reviews. 2017; 3(9): CD010673.

[4]. Heslop K, Newton J, Baker C, Burns G, Carrick-Sen D, De Soyza A. Effectiveness of cognitive behavioural therapy (CBT) interventions for anxiety in patients with chronic obstructive pulmonary disease (COPD) undertaken by respiratory nurses: the COPD CBT CARE study: (ISRCTN55206395) [J]. BMC pulmonary medicine. 2013; 13(62-62).

[5]. Yohannes AM, Baldwin RC and Connolly MJ. Depression and anxiety in elderly patients with chronic obstructive pulmonary disease [J]. Age Ageing. 2006; 35(5):457-9.

[6]. Yohannes AM, Kaplan A and Hanania NA. Anxiety and Depression in Chronic Obstructive Pulmonary Disease: Recognition and Management [J].Cleveland Clinic Journal of Medicine. 2018; 85 (2 Suppl 1):S11-S18.

[7]. Regvat J, Žmitek A, Vegnuti M, Košnik M, Šuškovič S. Anxiety and depression during hospital treatment of exacerbation of chronic obstructive pulmonary disease[J]. Journal of International Medical Research. 2011;39(3): 1028-1038.

[8]. Montserrat-Capdevila J, Godoy P, Marsal JR, Ortega M, Pifarré J, Alsedà M et al. Mental disorders in chronic obstructive pulmonary diseases[J]. Perspectives in Psychiatric Care. 2018; 54(3): 398-404.

[9]. Atlantis E, Fahey P, Cochrane B, Smith S, et al. Bidirectional Associations Between Clinically Relevant Depression or Anxiety and COPD: A Systematic Review and Meta-analysis[J]. Chest. 2013; 144(3):766-777.

[10]. Yohannes AM, Baldwin RC and Connolly MJ. Depression and anxiety in elderly outpatients with chronic obstructive pulmonary disease: prevalence, and validation of the BASDEC screening questionnaire[J]. Int J Geriatr Psychiatry. 2000; 15(12):1090-6.

[11]. Baraniak A and Sheffield D. The efficacy of psychologically based interventions to improve anxiety, depression and quality of life in COPD: a systematic review and meta-analysis[J]. Patient Educ Couns. 2011; 83(1):29-36.

[12]. Livermore N, Dimitri A, Sharpe L, McKenzie DK, Gandevia SC, Butler JE, et al. Cognitive behaviour therapy reduces dyspnoea ratings in patients with chronic obstructive pulmonary disease (COPD) [J]. Respiratory Physiology \& Neurobiology. 2015; 216(35-42).

[13]. Doyle C, Bhar S, Fearn M, Ames D, Osborne D, You E, et al. The impact of telephone-delivered cognitive behaviour therapy and befriending on mood disorders in people with chronic obstructive pulmonary disease: A randomized controlled trial[J]. British Journal of Health Psychology. 2017; 22(3): 542-556.

[14]. Panagioti M, Scott C, Blakemore A, Coventry PA. Overview of the prevalence, impact, and management of depression and anxiety in chronic obstructive pulmonary disease [J]. Int J Chron Obstruct Pulmon Dis. 2014, 2014(default):1289-1306.

[15]. Tselebis A, Pachi A, llias I, Kosmas E, Bratis D, Moussas G, et al. Strategies to improve anxiety and depression in patients with COPD: a mental health perspective [J]. Neuropsychiatric Disease \& Treatment. 2016; 12(Issue 1):297-328.

[16]. Moher D, Liberati A, Tetzlaff J, Altman DG; PRISMA Group. Preferred reporting items for systematic reviews and meta-analyses: the PRISMA statement [J]. Ann Intern Med. 2009; 151(4):264-269.

[17]. Julian PT Higgins, Green S. Cochrane Handbook for Systematic Reviews of Interventions[M]// Cochrane handbook for systematic reviews of interventions /. 2008.

[18]. de Godoy DV and de Godoy RF. A randomized controlled trial of the effect of psychotherapy on anxiety and depression in chronic obstructive pulmonary disease [J]. Arch Phys Med Rehabil. 2003; 84(8):1154-7.

[19]. Farver-Vestergaard I, O'Toole MS, O'Connor M, et al. Mindfulness-based cognitive therapy in COPD: A cluster randomised controlled trial[J]. European Respiratory Journal. 2018; 51(2):

[20]. Heslop-Marshall K, Baker C, Carrick-Sen D, Newton J, Echevarria C, Stenton C, et al. Randomised controlled trial of cognitive behavioural therapy in COPD[J]. ERJ Open Research. 2018; 4(4): 00094-2018.

[21]. Howard C and Dupont S. The COPD breathlessness manual': a randomised controlled trial to test a cognitive-behavioural manual versus information booklets on health service use, mood and health status, in patients with chronic obstructive pulmonary disease[J]. Npj Primary Care Respiratory Medicine. 
$2014 ; 24(1): 14076$

[22]. Hynninen MJ1, Bjerke N, Pallesen S, Bakke PS, Nordhus IH. A randomized controlled trial of cognitive behavioral therapy for anxiety and depression in COPD [J]. Respir Med. 2010; 104(7): 986-994.

[23]. Kunik ME, Braun U, Stanley MA, Wristers K, Molinari V, Stoebner D, et al. One session cognitive behavioural therapy for elderly patients with chronic obstructive pulmonary disease [J]. Psychological Medicine. 2001; 31(4):717.

[24]. Kunik ME, Veazey C, Cully JA, Souchek J, Graham DP, Hopko D, et al. COPD education and cognitive behavioral therapy group treatment for clinically significant symptoms of depression and anxiety in COPD patients: a randomized controlled trial [J]. Psychological Medicine. 2008; 38(3):385-396.

[25]. Lamers F, Jonkers CC, Bosma H, Chavannes NH, Knottnerus JA, van Eijk JT. Improving quality of life in depressed COPD patients: effectiveness of a minimal psychological intervention[J]. COPD. 2010; 7(5):315-22.

[26]. Alison P and Roger B. Examining the relationship between anxiety and depression and exacerbations of COPD which result in hospital admission: a systematic review[J]. International Journal of Chronic Obstructive Pulmonary Disease. 2014; 2014(9): 315-330.

[27]. Yohannes AM, Kaplan A and Hanania NA. COPD in Primary Care: Key Considerations for Optimized Management: Anxiety and Depression in Chronic Obstructive Pulmonary Disease: Recognition and Management [J]. J Fam Pract. 2018; 67(2 Suppl):S11-s18.

[28]. Dua R, Das A, Kumar A, Kumar S, Mishra M, Sharma K. Association of comorbid anxiety and depression with chronic obstructive pulmonary disease[J].Lung India. 2018; 35(1):31-36.

[29]. Fritzsche A, Clamor A and Leupoldt AV. Effects of medical and psychological treatment of depression in patients with COPD - A review [J]. Respir Med. 2011; 105(10): 1422-1433.

[30]. Yohannes AM and Alexopoulos GS. Pharmacological treatment of depression in older patients with chronic obstructive pulmonary disease: impact on the course of the disease and health outcomes [J]. Drugs \& Aging. 2014; 31(7):483-492.

[31]. Yohannes AM and Alexopoulos GS. Depression and anxiety in patients with COPD [J]. European Respiratory Review An Official Journal of the European Respiratory Society. 2014; 23(133):345-9.

[32]. Leupoldt AV and Janssens T. Could targeting disease specific fear and anxiety improve COPD outcomes?[J]. Expert Review of Respiratory Medicine. 2016; 10(8):1-3.

[33]. Haddad M. Depression in adults with a chronic physical health problem: Treatment and management[J]. International Journal of Nursing Studies. 2009; 46(11):1411-1414.

[34]. Smith SM, Sonego S, Ketcheson L, Larson JL. A review of the effectiveness of psychological interventions used for anxiety and depression in chronic obstructive pulmonary disease [J]. Bmj Open Respiratory Research. 2014; 1(1):e000042.

[35]. Farver-Vestergaard I, Jacobsen D and Zachariae R. Efficacy of psychosocial interventions on psychological and physical health outcomes in chronic obstructive pulmonary disease: a systematic review and meta-analysis[J]. Psychotherapy \& Psychosomatics. 2015; 84(1):37-50.

[36]. Coventry PA and Gellatly JL. Improving outcomes for COPD patients with mild-to-moderate anxiety and depression: a systematic review of cognitive behavioural therapy[J]. Br J Health Psychol. 2011; 13(3):381-400.

[37]. Thiart H, Ebert DD, Lehr D, Nobis S, Buntrock C, Berking M et al. Internet-Based Cognitive Behavioral Therapy for Insomnia: A Health Economic Evaluation[J]. Sleep. 2016; 39(10):1769-1778.

[38]. Ahern E, Kinsella S and Semkovska M. Clinical efficacy and economic evaluation of online cognitive behavioral therapy for major depressive disorder: a systematic review and meta-analysis[J]. Expert Rev Pharmacoecon Outcomes Res. 2017; 18(1):25-41.

\section{Tables}


Table 1. Baseline Characteristics of Included Studies

\begin{tabular}{|c|c|c|c|c|c|c|c|c|c|c|}
\hline \multirow[t]{2}{*}{ Study } & \multirow[t]{2}{*}{ Year } & \multirow[t]{2}{*}{ State } & \multirow{2}{*}{$\begin{array}{l}\text { No. of } \\
\text { Patients } \\
\text { (Start) }\end{array}$} & \multirow{2}{*}{$\begin{array}{l}\text { No. of } \\
\text { Patients } \\
\text { (End) }\end{array}$} & \multicolumn{2}{|c|}{ Cognitive therapy group } & \multicolumn{2}{|c|}{ Control group } & \multirow{2}{*}{$\begin{array}{l}\text { Anxiety } \\
\text { Measure }\end{array}$} & \multirow{2}{*}{$\begin{array}{r}\text { Depressio } \\
\text { Measure }\end{array}$} \\
\hline & & & & & Age (years) & $\begin{array}{l}\mathrm{FEV}_{1}(\% \\
\text { Predicted })\end{array}$ & Age (years) & $\begin{array}{l}\mathrm{FEV}_{1}(\% \\
\text { Predicted })\end{array}$ & & \\
\hline
\end{tabular}

\begin{tabular}{|c|c|c|c|c|c|c|c|c|c|c|}
\hline Kunik & 2008 & USA & 238 & 238 & $66.1 \pm 10.1$ & $45.3 \pm 16.8$ & $66.5 \pm 10.4$ & $46.8 \pm 17.5$ & BAI & $\mathrm{BDI}$ \\
\hline Lamers & 2010 & Netherlands & 187 & 187 & $70.5 \pm 6.5$ & NA & $71.5 \pm 7.1$ & NA & SCL & BDI \\
\hline Hynninen & 2010 & Norway & 51 & 51 & $59.3 \pm 7.6$ & $59.8 \pm 21.1$ & $62.6 \pm 9.9$ & $57.8 \pm 25.8$ & BAI & BDI \\
\hline Howard & 2014 & UK & 222 & 222 & $71.2 \pm 10.4$ & $55.9 \pm 15.7$ & $73.2 \pm 11.4$ & $59.6 \pm 15.9$ & HADS & HADS \\
\hline Livermore & 2015 & Australia & 31 & 31 & $72 \pm 6$ & NA & $72 \pm 6$ & NA & HADS & HADS \\
\hline Doyle & 2017 & Denmark & 110 & 110 & $68.5 \pm 9.4$ & NA & $67.0 \pm 9.1$ & NA & BAI & PHQ-9 \\
\hline $\begin{array}{c}\text { Farver- } \\
\text { Vestergaard }\end{array}$ & 2018 & Denmark & 82 & 67 & $66.67 \pm 8.03$ & $37.50 \pm 12.09$ & $67.67 \pm 7.54$ & $37.94 \pm 11.62$ & HADS & HADS \\
\hline $\begin{array}{l}\text { Heslop- } \\
\text { Marshall }\end{array}$ & 2018 & UK & 279 & 236 & $66 \pm 10.2$ & NA & $67 \pm 9.6$ & NA & HADS & HADS \\
\hline de Godoy & 2003 & Brazil & 30 & 30 & $62.1 \pm 14.9$ & NA & $58.8 \pm 11.8$ & NA & BAI & BDI \\
\hline Kunik & 2001 & USA & 48 & 48 & $\geq 60$ & NA & $\geq 60$ & NA & BAI & GDS \\
\hline
\end{tabular}
checklist-90; HADS, hospital anxiety and depression scale; PHQ-9, patient health questionnaire-9; GDS, geriatric depression scale.

Table 2.Description of Interventions

\begin{tabular}{|c|c|c|c|c|c|c|}
\hline \multirow[t]{2}{*}{ Study } & \multirow[t]{2}{*}{ Year } & \multicolumn{2}{|c|}{ Cognitive therapy group } & \multicolumn{2}{|r|}{ Control group } & \multirow[t]{2}{*}{ Duration } \\
\hline & & Methods & Frequency & Methods & Frequency & \\
\hline Kunik & 2008 & group CBT & eight 1-h sessions & $\begin{array}{c}\text { Health } \\
\text { education }\end{array}$ & $\begin{array}{l}\text { 45-minute lectures/15-minute } \\
\text { discussions }\end{array}$ & $8, \mathrm{w}$ \\
\hline Lamers & 2010 & Individual CBT & $\begin{array}{l}1 \text { to10 times at } 12 \text { weeks, } 60- \\
\text { min sessions }\end{array}$ & usual care & NA & $12, \mathrm{w}$ \\
\hline Hynninen & 2010 & group CBT & $\begin{array}{c}120 \text {-min sessions, } 3 \\
\text { times/week }\end{array}$ & usual care & 2 times / week & $4, \mathrm{w}$ \\
\hline Howard & 2014 & group CBT & $\begin{array}{l}\text { 60-min sessions, } 1 \\
\text { times/day }\end{array}$ & usual care & NA & $5, \mathrm{w}$ \\
\hline Livermore & 2015 & Individual CBT & $\begin{array}{l}\text { 60-min sessions, } 4 \\
\text { times/week }\end{array}$ & usual care & NA & $8, \mathrm{w}$ \\
\hline Doyle & 2017 & $\begin{array}{l}\text { telephone-administered CBT } \\
\text { intervention }\end{array}$ & 8 times/week & usual care & 8 times/week & $8, w$ \\
\hline $\begin{array}{c}\text { Farver- } \\
\text { Vestergaard }\end{array}$ & 2018 & Mindfulness-based CBT & $\begin{array}{c}\text { 105-min sessions, } 8 \\
\text { times/week }\end{array}$ & $\begin{array}{l}\text { blank } \\
\text { control }\end{array}$ & NA & $8, \mathrm{w}$ \\
\hline $\begin{array}{l}\text { Heslop- } \\
\text { Marshall }\end{array}$ & 2018 & Nurse-led CBT & $\begin{array}{c}\text { 30-min sessions, once every } 4 \\
\text { to } 6 \text { weeks }\end{array}$ & usual care & NA & $3, \mathrm{mo}$ \\
\hline de Godoy & 2003 & group CBT & $\begin{array}{c}1 \\
\text { times/week }\end{array}$ & $\begin{array}{l}\text { blank } \\
\text { control }\end{array}$ & NA & $12, \mathrm{w}$ \\
\hline Kunik & 2001 & group CBT & 2 hour session & $\begin{array}{l}\text { Health } \\
\text { education }\end{array}$ & 2 hour education session & $2, \mathrm{~h}$ \\
\hline
\end{tabular}


Table 3. Outcome Data Summary

\begin{tabular}{|c|c|c|c|c|c|c|c|c|c|c|c|}
\hline \multirow[t]{2}{*}{ Outcome } & \multirow[t]{2}{*}{ Instrument } & \multirow[t]{2}{*}{ Study } & \multirow[t]{2}{*}{ Year } & \multicolumn{4}{|c|}{ Cognitive therapy group } & \multicolumn{4}{|c|}{ Control group } \\
\hline & & & & $\begin{array}{c}\text { No. of } \\
\text { Patients }\end{array}$ & Baseline & $\begin{array}{c}\text { No. of } \\
\text { Patients }\end{array}$ & $\begin{array}{c}\text { Post- } \\
\text { treatment }\end{array}$ & $\begin{array}{c}\text { No. of } \\
\text { Patients }\end{array}$ & Baseline & $\begin{array}{c}\text { No. of } \\
\text { Patients }\end{array}$ & $\begin{array}{l}\text { Post } \\
\text { treatm }\end{array}$ \\
\hline \multirow[t]{10}{*}{ Anxiety } & BAI & Kunik & 2008 & 118 & $22.67 \pm 14.22$ & 118 & $15.89 \pm 14.87$ & 120 & $22.67 \pm 13.84$ & 120 & $17.46 \pm 1$ \\
\hline & SCL & Lamers & 2010 & 96 & $20.6 \pm 6.2$ & 61 & $20.76 \pm 0.73$ & 91 & $20.4 \pm 7.3$ & 66 & $21.43 \pm 0$ \\
\hline & BAI & Hynninen & 2010 & 25 & $17.5 \pm 7.3$ & 25 & $12.7 \pm 6.8$ & 26 & $17.5 \pm 9.5$ & 26 & $18.7 \pm$ \\
\hline & HADS & Howard & 2014 & 112 & $8.4 \pm 4.5$ & 112 & $6.8 \pm 3.7$ & 110 & $7.8 \pm 4.2$ & 110 & $6.8 \pm 3$ \\
\hline & HADS & Livermore & 2015 & 18 & $5.3 \pm 3.0$ & 18 & NA & 13 & $5.8 \pm 2.7$ & 14 & NA \\
\hline & BAI & Doyle & 2017 & 54 & $20.0 \pm 11.2$ & 54 & $18.4 \pm 11.8$ & 56 & $20.9 \pm 10.4$ & 56 & $17.2 \pm$ \\
\hline & HADS & $\begin{array}{c}\text { Farver- } \\
\text { Vestergaard }\end{array}$ & 2018 & 37 & $7.72 \pm 4.72$ & 30 & $6.80 \pm 3.86$ & 45 & $7.57 \pm 4.12$ & 37 & $7.92 \pm 4$ \\
\hline & HADS & $\begin{array}{l}\text { Heslop- } \\
\text { Marshall }\end{array}$ & 2018 & 130 & $12.3 \pm 3.19$ & 115 & $8.8 \pm 4.49$ & 140 & $12.0 \pm 2.94$ & 121 & $10.0 \pm 4$ \\
\hline & BAI & de Godoy & 2003 & 14 & $12.9 \pm 6.9$ & 14 & $4.2 \pm 3.8$ & 16 & $10.9 \pm 9.8$ & 16 & $9.2 \pm 8$ \\
\hline & BAI & Kunik & 2001 & 21 & $15.3 \pm 9.2$ & 21 & $12.6 \pm 8.7$ & 27 & $10 \pm 6.8$ & 27 & $11.9 \pm 7$ \\
\hline \multirow[t]{10}{*}{ Depression } & BDI & Kunik & 2008 & 118 & $23.44 \pm 12.49$ & 118 & $\begin{array}{r}14.19 \\
\pm 13.69\end{array}$ & 120 & $21.12 \pm 12.09$ & 120 & $14.54 \pm 1$ \\
\hline & BDI & Lamers & 2010 & 96 & $17.1 \pm 6.5$ & 64 & $15.45 \pm 0.8$ & 91 & $18.3 \pm 7.2$ & 68 & $17.31 \pm$ \\
\hline & BDI & Hynninen & 2010 & 25 & $20.7 \pm 8.6$ & 25 & $14.8 \pm 7.8$ & 26 & $20.5 \pm 9.7$ & 26 & $19.5 \pm$ \\
\hline & HADS & Howard & 2014 & 112 & $8.8 \pm 3.7$ & 112 & $6.0 \pm 3.5$ & 110 & $8.6 \pm 3.5$ & 110 & $7.8 \pm 3$ \\
\hline & HADS & Livermore & 2015 & 18 & $3.8 \pm 2.0$ & 18 & NA & 13 & $4.6 \pm 2.7$ & 13 & NA \\
\hline & PHQ-9 & Doyle & 2017 & 54 & $12.6 \pm 6$ & 54 & $9.6 \pm 6$ & 56 & $11.2 \pm 6.8$ & 56 & $9.5 \pm 7$ \\
\hline & HADS & $\begin{array}{c}\text { Farver- } \\
\text { Vestergaard }\end{array}$ & 2018 & 37 & $6.32 \pm 3.67$ & 30 & $5.33 \pm 3.77$ & 45 & $5.90 \pm 4.10$ & 37 & $6.26 \pm 4$ \\
\hline & HADS & $\begin{array}{l}\text { Heslop- } \\
\text { Marshall }\end{array}$ & 2018 & 130 & NA & NA & NA & 140 & NA & NA & NA \\
\hline & BDI & de Godoy & 2003 & 14 & $13.7 \pm 8.9$ & 14 & $5 \pm 4.5$ & 16 & $14.9 \pm 11.5$ & 16 & $12.3 \pm 1$ \\
\hline & GDS & Kunik & 2001 & 21 & $11.5 \pm 7.3$ & 21 & $9.4 \pm 6.5$ & 27 & $7.7 \pm 5.4$ & 27 & $8.8 \pm 7$ \\
\hline
\end{tabular}

Abbreviations:NA,data Not Available;BAI,beck anxiety Inventory;BDI,beck depression rating scale;SCL,anxiety subscale of the symptom checkli $90 ;$ HADS, hospital anxiety and depression scale;PHQ-9 , patient health questionnaire-9;GDS, geriatric depression scale.

\section{Figures}

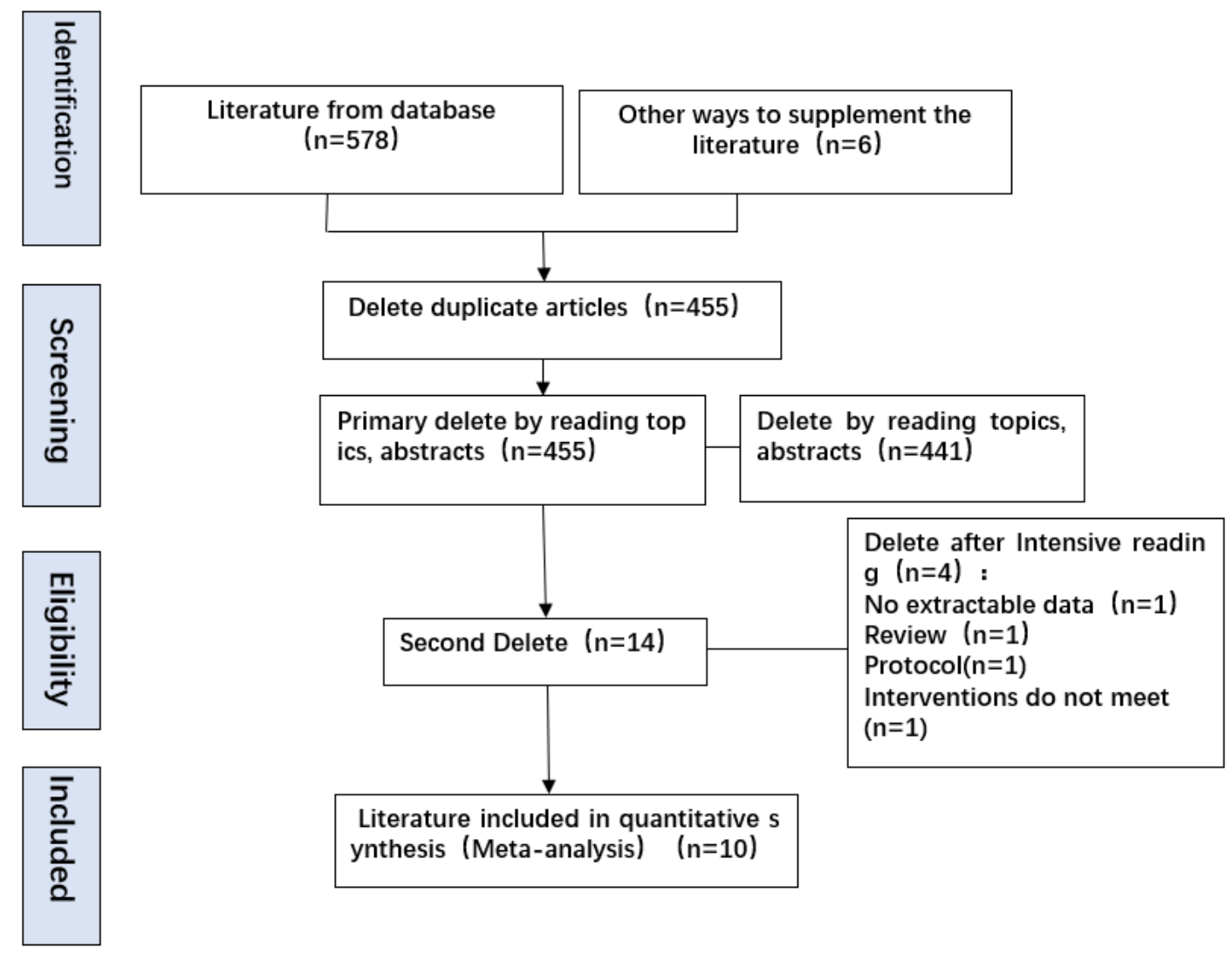

Figure 1

Flowchart of selection of studies for inclusion in meta-analysis. 
Random sequence generation (selection bias)

Allocation concealment (selection bias)

Blinding of participants and personnel (performance bias)

Blinding of outcome assessment (detection bias)

Incomplete outcome data (attrition bias)

Selective reporting (reporting bias)

Other bias
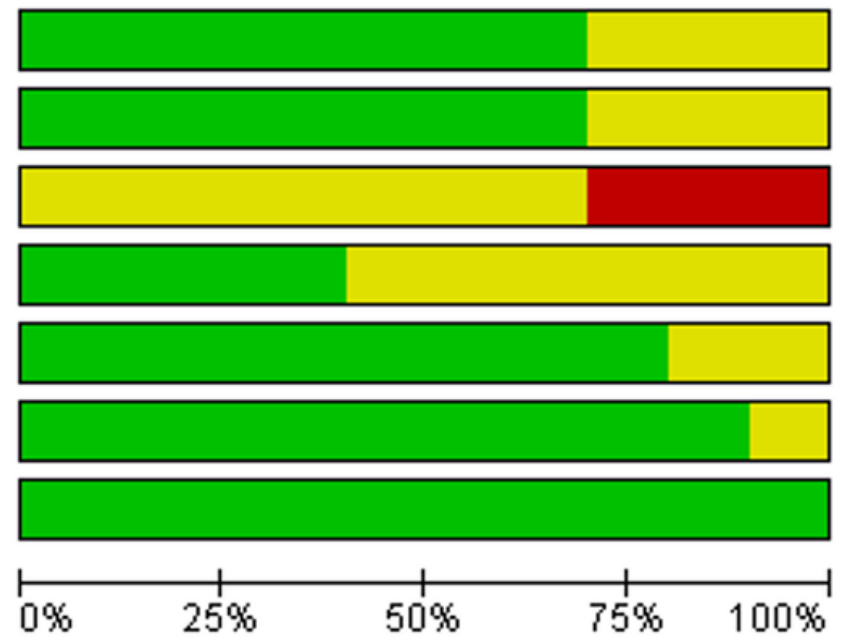

Low risk of bias

Unclear risk of bias

High risk of bias

Figure 2

Risk of bias graph

\begin{tabular}{|c|c|c|c|c|c|c|c|c|c|c|}
\hline 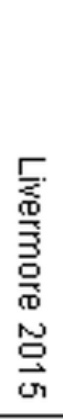 & 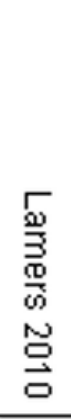 & 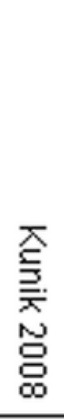 & 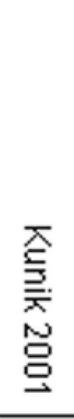 & 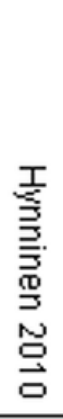 & 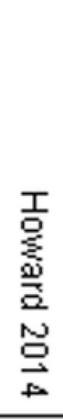 & 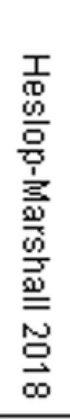 & 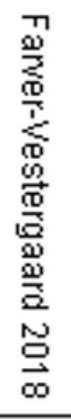 & 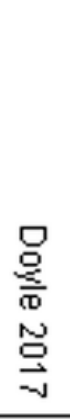 & 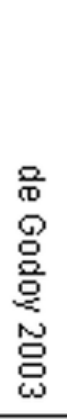 & \\
\hline$\cdot v$ & + & + & + & $\sim$ & + & + & + & + & $\cdot v$ & Random sequence generation (selection bias) \\
\hline$\cdot \nu$ & + & + & $\cdot$ & + & + & + & + & + & $\cdot v$ & Allocation concealment (selection bias) \\
\hline$\cdot$ & $\cdot \nu$ & & $\cdot \nu$ & & $\cdot v$ & $\sim$ & & $\sim$ & $\cdot v$ & Blinding of participants and personnel (performance bias) \\
\hline$\cdot v$ & + & + & $\cdot v$ & $\cdot v$ & + & $\cdot v$ & $\cdot v$ & + & $\cdot v$ & Blinding of outcome assessment (detection bias) \\
\hline+ & + & + & + & + & + & $\cdot v$ & $\cdot v$ & + & + & Incomplete outcome data (attrition bias) \\
\hline+ & + & + & + & + & + & + & + & + & $\cdot v$ & Selective reporting (reporting bias) \\
\hline+ & + & + & + & + & + & + & + & + & + & Other bias \\
\hline
\end{tabular}

Figure 3

Risk of bias summary 


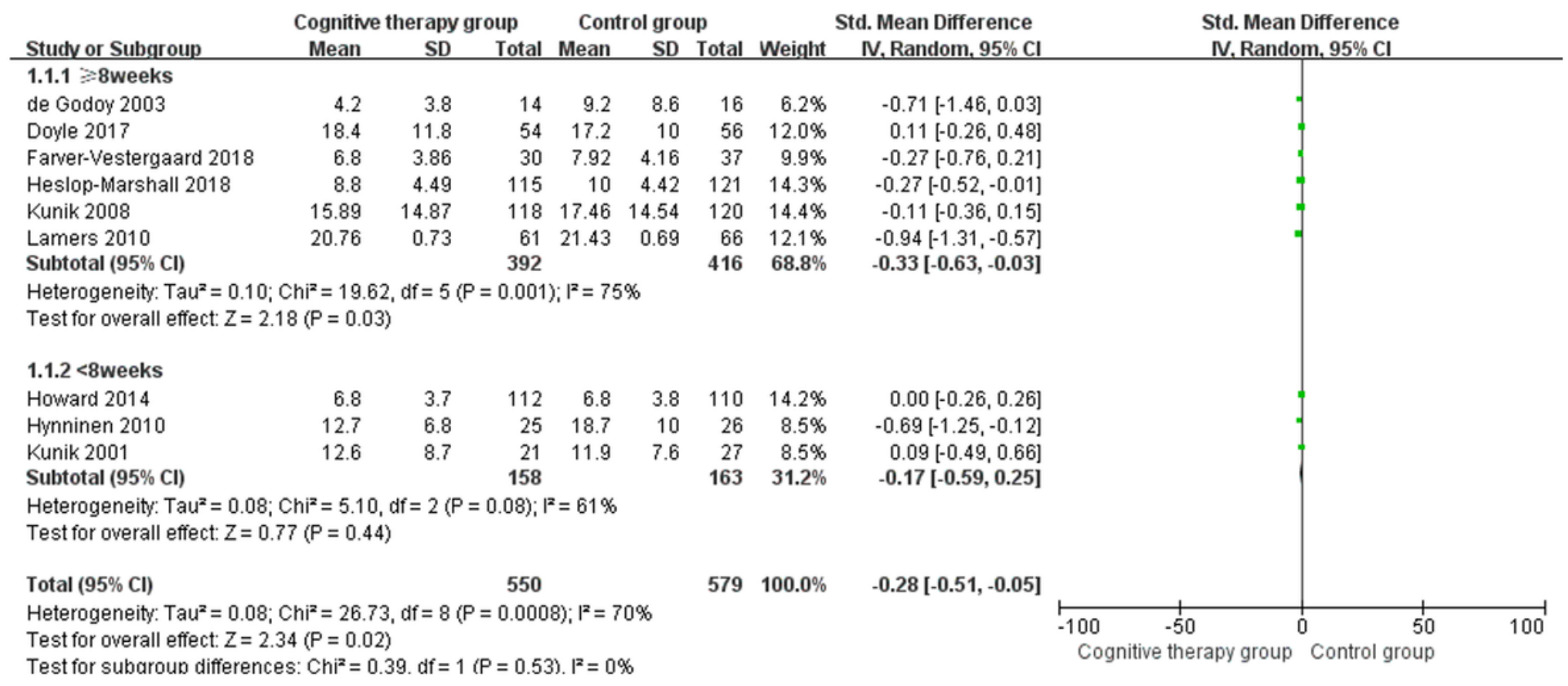

\section{Figure 4}

Pooled effect of cognitive therapy group compared with control group on symptoms of anxiety in people with COPD.

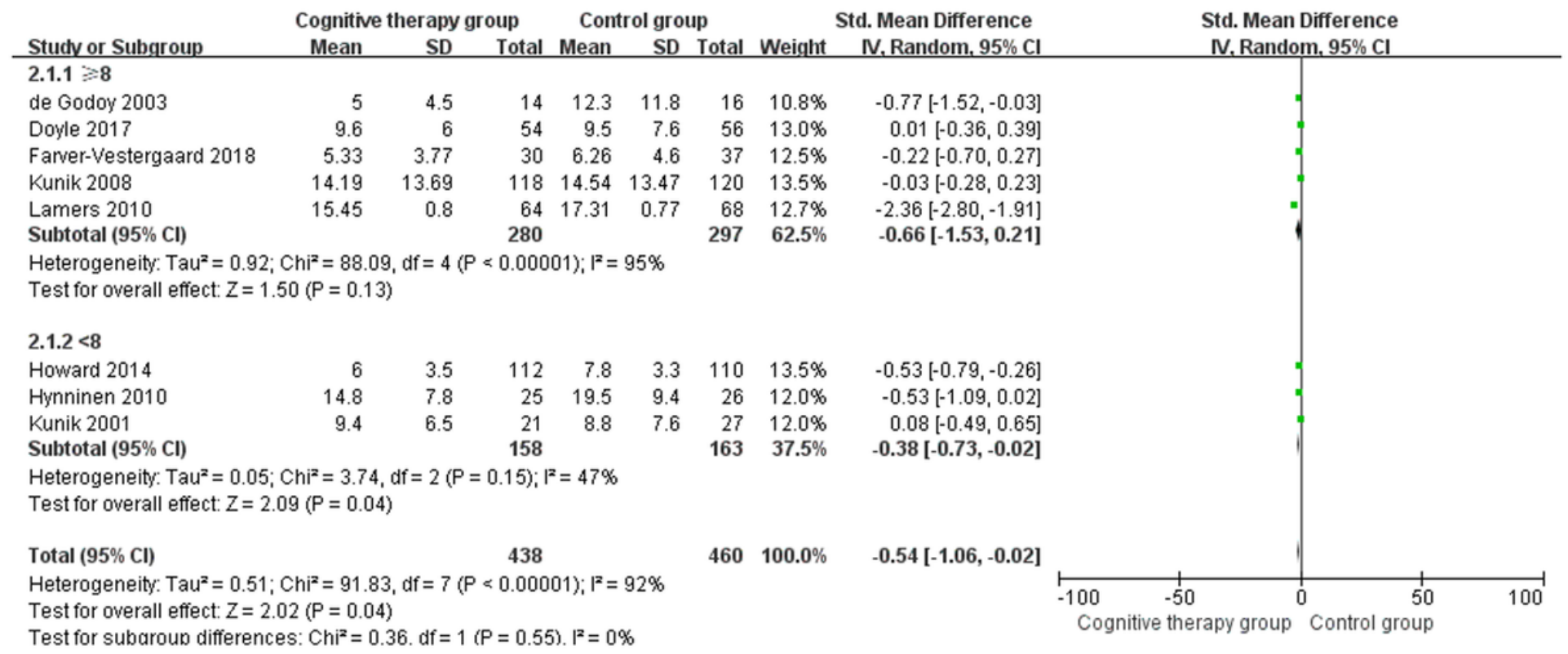

\section{Figure 5}

Pooled effect of cognitive therapy group compared with control group on symptoms of depression in people with COPD. 
Begg's funnel pl ot with pseudo $95 \%$ confi dence I i mits

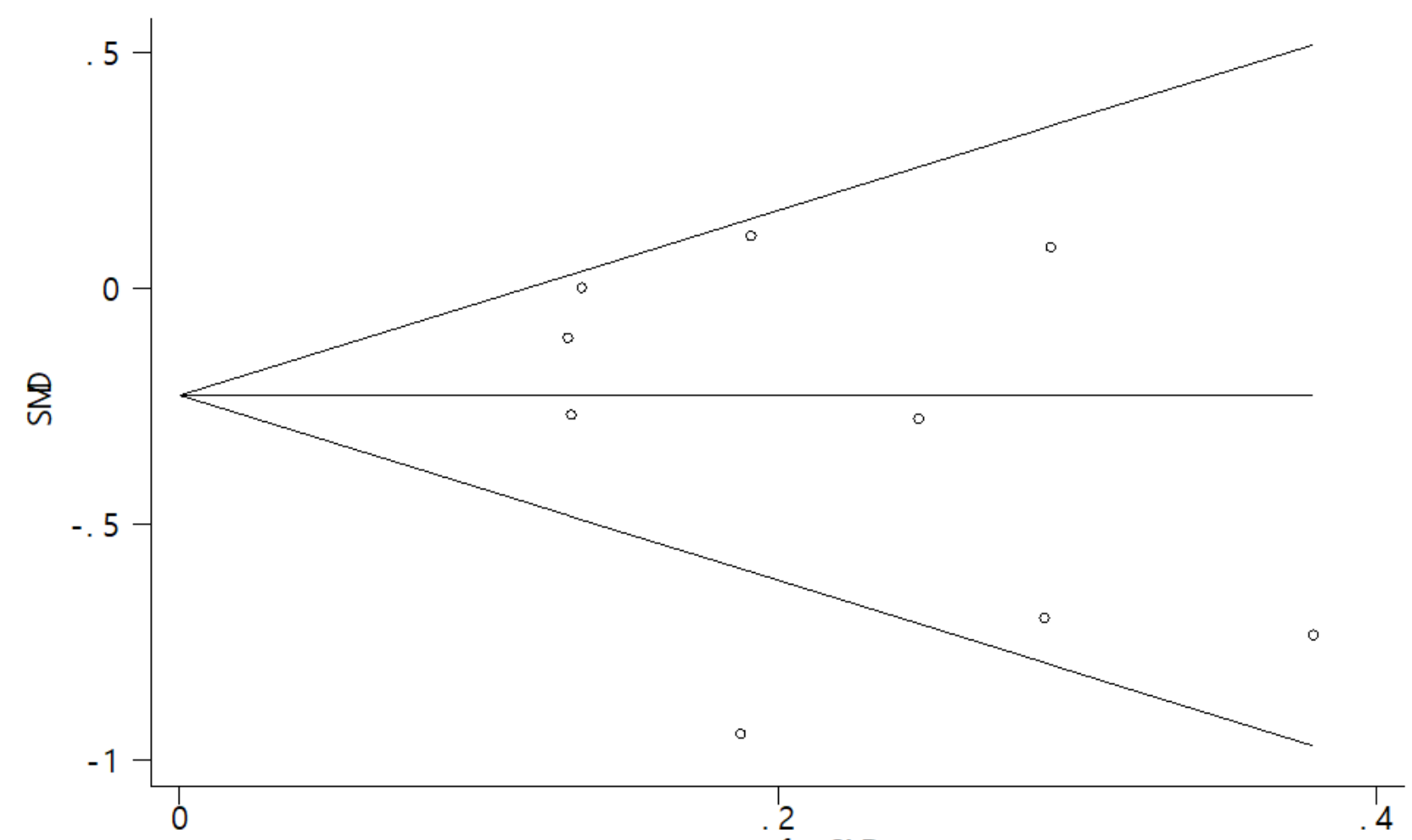

s. e. of: $S M D$

Figure 6

Begg's funnel plot of cognitive therapy group compared with control group on symp-toms of anxiety in people with COPD 
Begg's funnel pl ot wi th pseudo $95 \%$ conf $\mathrm{i}$ dence I i mits

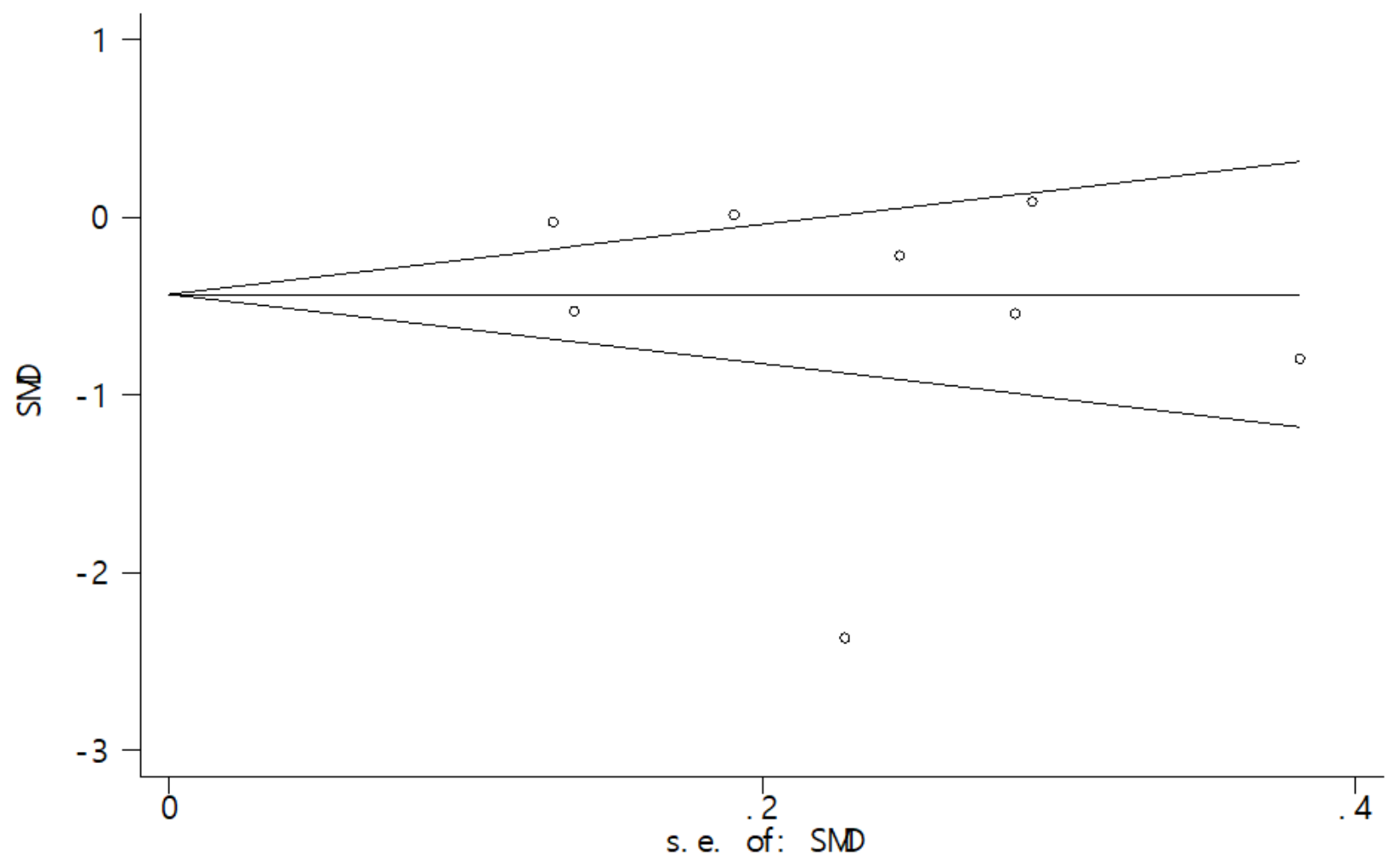

Figure 7

Begg's funnel plot of cognitive therapy group compared with control group on symp-toms of depression in people with COPD

\section{Supplementary Files}

This is a list of supplementary files associated with this preprint. Click to download.

- PRISMAchecklist.pdf 